\title{
Psychosocial adjustment among patients with ostomy: a survey in stoma clinics, Nepal
}

This article was published in the following Dove Press journal:

Nursing: Research and Reviews

29 August 2016

Number of times this article has been viewed

\section{Sital Gautam' \\ Surya Koirala² \\ Anju Poudel' \\ Dipak Paudel ${ }^{3}$}

'Department of Nursing, Nepal Medical College, ${ }^{2}$ Department of Nursing, Institute of Medicine, Tribhuvan University, Nursing Campus Maharajgunj, ${ }^{3}$ Department of Medicine, People's Medical College, Kathmandu, Nepal

Video abstract

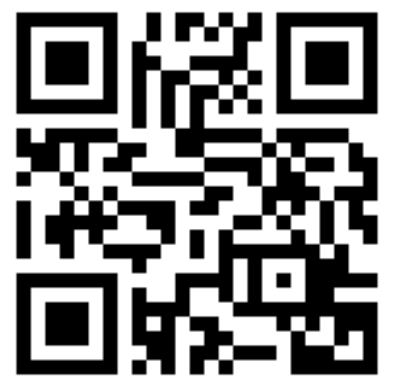

Point your SmartPhone at the code above. If you have a QR code reader the video abstract will appear. Or use: http://youtu.be/t9rgj7DFzkl
Correspondence: Sital Gautam Mid Baneshwor-34, Kathmandu, Nepal Tel +977984I 676324

Email gautamsital@hotmail.com
Background: Ostomy changes the overall lifestyle of a person, and ostomates have been identified as a chronic illness population frequently experiencing adjustment problems.

Purpose: The aim of this study was to determine the psychosocial adjustment and its predictors among patients with ostomy in Nepal.

Patients and methods: A descriptive cross-sectional study was conducted in two stoma clinics of Nepal. Patients who had a colostomy, ileostomy, or urostomy, visited the selected stoma clinics during the data collection period, and who had ostomy for at least 6 months before data collection were included in the study. A total of 130 patients were included in this study. Data on sociodemographic and clinical variables were collected. Psychosocial adjustment score was measured using Ostomy Adjustment Inventory-23.

Results: A total of 130 patients ( 80 males and 50 females) were included in the study. The mean age of the patients was 51 years, ranging from 23 to 78 years. The study findings revealed that mean \pm SD adjustment score was $41.49 \pm 13.57$, indicating moderate impairment in the psychosocial adjustment among ostomates, and the mean $\pm \mathrm{SD}$ scores of acceptance, anxious preoccupation, social engagement, and anger were $22.01 \pm 6.99,8.75 \pm 3.89,5.38 \pm 3.41$, $5.35 \pm 1.62$, respectively. Four variables contributed significantly to the final model, explaining $46.8 \%$ of variance in the psychosocial adjustment score $\left(R^{2}=0.468, F(4,125)=27.53, P<0.001\right)$. Perceived lack of family support $(\beta=-0.367, P<0.001)$, total dependence on others to care for ostomy $(\beta=-0.357, P<0.001)$, and unemployment $(\beta=-0.144, P=0.032)$ significantly predicted lower psychosocial adjustment scores. However, increased time since ostomy surgery $(\beta=0.361$, $P<0.001)$ significantly predicted higher psychosocial adjustment scores.

Conclusion: Ostomy often affects all aspects of a patient's life; however, emotional, sexual, and social lives are the most affected areas. Importantly, the focus of treatment for ostomates should expand beyond the physical boundaries and should consider psychosocial concerns as well.

Keywords: ostomy, stoma surgery, ostomates, psychosocial adjustment, quality of life

\section{Introduction}

Ostomy has a pervasive impact on every aspect of a patient's life; however, the major long-term impact is on psychological and social functioning. These kinds of extensive surgeries are often necessary to manage a variety of gastrointestinal or genitourinary etiologies such as colon or rectal cancer, injury, inflammatory bowel disease, peritonitis, obstruction, radiation enteritis, ischemia, fistula, and perianal sepsis. ${ }^{1}$ Although ostomy is a lifesaving surgery, there is strong evidence of psychosocial maladjustment in ostomates globally. One of the first efforts to examine the range of postsurgical adjustment difficulties in ostomates was put forward in a very early 
prospective study in the Netherlands. ${ }^{2}$ The study compared psychosocial adjustment and survival rate of 59 ostomates with that of 64 patients with no stoma. The measurement was taken at 4 months, 1 year, and 4 years after surgery using Psychosocial Adjustment to Illness Scale - Self-Report. The study found that compared to patients with no stoma, patients who underwent stoma surgery experienced significantly more psychosocial problems particularly with respect to sexuality and work during the first 4 months. However, these problems had not been reported 1 year after the surgery, and both the groups had the same level of psychosocial problems after 4 years. The significant inference was that patients with poor early psychosocial adjustment scores (at 4 months) were at a significantly high risk of dropping out because of death and terminal status. This finding raises the need for psychosocial assessment and long-term guidance of ostomates.

The most striking change since the nineteenth century has been the availability of improved ostomy equipment, but the psychosocial problems, taboos, and stigma still exist. Consequently, a study conducted in the $\mathrm{UK}^{3}$ demonstrated that among 112 ostomates $37 \%-47 \%$ had problems related to work, sexual dysfunction, finance, family relations, and emotion. Additionally, $>50 \%$ had a reduction in social activities. Similarly, another study ${ }^{4}$ included 54 Chinese patients with colostomy from an outpatient clinic and used Ostomates Adjustment Inventory to assess the level of psychosocial adjustment. The results showed a mean $\pm \mathrm{SD}$ adjustment score of $49.84 \pm 12.486$, indicating a moderate level of psychosocial adjustment. However, the score was the lowest for social life adjustment, and this implies that despite the advancement in supplies and technologies since the nineteenth century, no significant changes have been reported in the adjustment problems faced by this group of patients.

Although the aforementioned studies showed moderate adjustment scores in ostomates, different findings were reported by many others in which ostomates reported good overall adjustment scores. A study conducted among 60 patients who underwent colostomy for at least 4 months at five hospitals in Chile reported good overall adjustment on social, occupational, and family concerns as measured by the Olbrisch Ostomy Adjustment Scale. However, $>50 \%$ reported marital problems. ${ }^{5}$ Similar findings were reported by another study ${ }^{6}$ using the same scale. Among 146 patients who had ostomy for $\geq 6$ months, mean $\pm \mathrm{SD}$ adjustment score was $159.5 \pm 26.2$, indicating good overall adjustment. Nevertheless, $43 \%$ of the patients indicated that their ostomy had a negative impact on their sex life. In a similar way, another study $^{7}$ adds further support by stating that the majority of the participants among 51 patients from the District Hospital in the UK had adjusted to their stoma after 6 months. Likewise, patients reported strong adjustment to extended family relationship, but poor adjustment to sexual relationship in another study. ${ }^{8}$

Thus, psychosocial adjustment in patients with ostomy worldwide shows conflicting results. The findings should be interpreted carefully because of varying conceptualization of psychosocial adjustment and the use of different assessment tools.

Furthermore, numerous determinants of the psychosocial adjustment in patients with ostomy have been identified worldwide. These include age, ${ }^{5,9}$ education, ${ }^{5,10}$ income change after surgery, ${ }^{2,8}$ family and social support, ${ }^{2,7,11,12}$ the form of stoma surgery, ${ }^{5}$ time since surgery, ${ }^{5,8}$ information about surgery, ${ }^{4,6}$ self-care ability, ${ }^{2,4,5,7,13}$ and distress about obtaining supplies. ${ }^{6}$

A large number of research studies have been conducted worldwide; however, only one study ${ }^{14}$ in Nepal has focused on psychosocial problems of ostomates. In an attempt to assess various problems faced by ostomates, a descriptive study was carried out in which 101 ostomates were interviewed using a structured questionnaire. The results of the study are as follows: psychological problems were demonstrated as $36 \%$ had significant amount of stress, $44 \%$ had an increased frequency of anger and irritation since surgery, and $10 \%$ required psychiatric consultation; social problems were depicted as $36.1 \%$ indicated that they were fearful about social reaction and $94.4 \%$ reported decreased social activities since surgery; and $27.8 \%$ confirmed that ostomy interfered with their sex life and marriage.

Yet, overall psychosocial adjustment of ostomates and its predictors have not been identified in Nepal. The condition of ostomates in Nepal is complicated further by lack of stoma clinics, proper stoma care therapist, and counseling facilities. In addition, transportation difficulties and unavailability of stoma equipment prevail.

Therefore, the study was carried out with the aim to answer three research questions: 1) What are the psychosocial adjustments for patients with ostomy? 2) Does the psychosocial adjustment differ by selected sociodemographic and clinical characteristics? and 3) What are the predictors of psychosocial adjustment among patients with ostomy?

\section{Patients and methods}

A descriptive cross-sectional study was carried out from April 2014 to June 2014. The study comprised of 130 patients ( 80 males and 50 females) aged 23-78 years (mean age, 51.04 years) visiting the selected stoma clinics of Nepal. The study was approved by the Institutional Review Board of Institute of Medicine, Tribhuvan University. Administrative approval was obtained from the authorities of selected hospitals and 
associations. Written informed consent was obtained from every patient before data collection. During the data collection period, all patients having ostomy visiting these stoma clinics, and who had ostomy at least 6 months before data collection were purposively selected for this study. In total, 150 patients visited the clinics, eight of these patients had their stoma less than 6 months before data collection, three declined to participate due to time constraints, and nine were visitors coming on behalf of patients to collect ostomy bags. Therefore, 130 patients who met the inclusion criteria were taken as the sample (response rate $=97.74 \%$ ).

Researchers (nurses) collected data through face-to-face interview in a separate location allocated for the staff of the ostomy clinics. It took $\sim 30$ minutes to collect data from each respondent.

\section{Tools for data collection}

\section{Part one (patient characteristics)}

Data obtained were related to:

- Sociodemographic characteristics (age, sex, employment status, and perceived family support).

- Clinical characteristics (reason for stoma, information about stoma before surgery, the form of surgery [planned vs emergency], type of stoma [ie, colostomy, urostomy, or ileostomy], time since surgery, treatment, complications, comorbidities, difficulty in obtaining supplies, and self-care efficacy).

\section{Part two (psychosocial adjustment)}

- Ostomy Adjustment Inventory-23 developed by Simmons et $\mathrm{a}^{15}$ was used to assess psychosocial adjustment, which is a Likert-type scale containing 20 items with four subscales: acceptance, anxious preoccupation, social engagement, and anger.

- Scoring: each item could be answered on a 5-point scale, where 0 indicates strongly disagree, and 4 indicates strongly agree. The total score was obtained from the sum of the scores of all items. The highest score possible was thus 80 and the lowest was 0 . Ten items had reversescoring, as they are negatively phrased. Higher scores indicated better adjustment.

- The decision to use this tool was based on its focus on long-term psychosocial adjustment and established psychometric properties. Cronbach's $\alpha$ was 0.93 for overall scale, $r=0.83$, and $a=0.87,0.74,0.80$, and 0.64 for acceptance, anxious preoccupation, social engagement, and anger subscales, respectively. ${ }^{16}$ Permission to use this tool was obtained from Kingsley Simmons, University of
Hertfordshire, Hertfordshire, UK. The tool was translated into Nepali language and then back-translated into English language by two independent bilingual translators. The back-translated tool was sent to the original author of the tool for verification (retention of the same meaning). Before conducting the study, the tool was pretested. The Cronbach's $a$ was 0.957 for overall scale, indicating the translated Nepali Likert-type scale was highly reliable.

\section{Statistical analysis}

Statistical Package for Social Sciences (Version 20; IBM Corporation, Armonk, NY, USA) was used for data analysis. Continuous variables were expressed using mean and standard deviation. Qualitative variables were described using frequency and percentage. Some of the quantitative data were converted into categorical data to facilitate the analysis. Normality of the quantitative variable was verified using Shapiro-Wilk test, and the data were found to be normally distributed $(P>0.05)$. Difference in psychosocial adjustment in the subgroups of patients according to sociodemographic and clinical variables was analyzed using independent sample $t$-test and one-way analysis of variance. The Pearson's correlation coefficient $(r)$ was calculated to assess the relationship among the psychosocial adjustment score and quantitative variables.

To determine the predictors of psychosocial adjustment, multiple linear regression was used. First, univariate analysis with the outcome measure (psychosocial adjustment) was carried out to determine the potential predictors. Variables significant in univariate analysis with an association of $P \leq 0.05$ were entered in the multivariate model. Finally, the best predictive model was constructed, using an enter method, deleting those variables that had the weakest association with the psychosocial adjustment score. Autocollinearity was tested by using Durbin-Watson test. The significance level $(P)$ was set at $\leq 0.05$ for inferential statistics.

\section{Results}

A total of 130 patients (80 males and 50 females) were included in the study. The mean age of the patients was 51.04 years, ranging from 23 to 78 years. Table 1 provides the sociodemographic and clinical characteristics of the patients.

\section{Research question I:What are the psychosocial adjustments for patients with ostomy?}

The mean \pm SD score of psychosocial adjustment scale was $41.49 \pm 13.57$ showing moderate impairment in the 
Table I Patient characteristics $(n=\mid 30)$

\begin{tabular}{|c|c|}
\hline Characteristics & Frequency (\%) \\
\hline \multicolumn{2}{|l|}{ Age, years } \\
\hline $20-39$ & $33(25.4)$ \\
\hline $40-59$ & $55(42.3)$ \\
\hline $60-79$ & $42(32.3)$ \\
\hline Mean age $(\mathrm{SD}), \min , \max$ & 51.04 (15.55), 23, 78 \\
\hline \multicolumn{2}{|l|}{ Sex } \\
\hline Male & $80(61.5)$ \\
\hline Female & $50(38.5)$ \\
\hline \multicolumn{2}{|l|}{ Employment status } \\
\hline Employed & $74(56.9)$ \\
\hline Unemployed & $56(43.1)$ \\
\hline \multicolumn{2}{|l|}{ Perceived support from family } \\
\hline Present & $102(78.5)$ \\
\hline Absent & $28(21.5)$ \\
\hline \multicolumn{2}{|l|}{ Reason for formation of stoma } \\
\hline Benign disease & $16(12.3)$ \\
\hline Cancer & II 4 (87.7) \\
\hline \multicolumn{2}{|l|}{ Information about stoma before surgery } \\
\hline Received & $99(76.2)$ \\
\hline Not received & $31(23.8)$ \\
\hline \multicolumn{2}{|l|}{ Form of surgery } \\
\hline Planned & $83(63.8)$ \\
\hline Emergency & $47(36.2)$ \\
\hline \multicolumn{2}{|l|}{ Type of ostomy } \\
\hline Colostomy & $85(65.4)$ \\
\hline lleostomy & $15(11.5)$ \\
\hline Urostomy & $30(23.1)$ \\
\hline \multicolumn{2}{|l|}{ Time since ostomy surgery } \\
\hline$\leqq 5$ years & $109(83.8)$ \\
\hline$>5$ years & $21(16.2)$ \\
\hline Mean duration, years (SD), min, $\max$ & 3.04 (4.25), 0.5, 25 \\
\hline \multicolumn{2}{|l|}{ Treatment } \\
\hline Under treatment & $48(36.9)$ \\
\hline Not under treatment & $82(63.1)$ \\
\hline \multicolumn{2}{|l|}{ Type of treatment $(n=48)$} \\
\hline Chemotherapy & $29(60.4)$ \\
\hline Chemotherapy + radiotherapy & II (22.9) \\
\hline Pharmacotherapy & $5(10.4)$ \\
\hline Radiotherapy & $3(6.3)$ \\
\hline \multicolumn{2}{|l|}{ Complication related to ostomy } \\
\hline Present & $50(38.5)$ \\
\hline Absent & $80(61.5)$ \\
\hline \multicolumn{2}{|l|}{ Type of complications $(n=50)$} \\
\hline Pain and discomfort & $20(40.0)$ \\
\hline Dermal irritation & $17(34.0)$ \\
\hline Bleeding & $9(18.0)$ \\
\hline Constipation & $4(8.0)$ \\
\hline \multicolumn{2}{|l|}{ Comorbidity } \\
\hline Present & $34(26.2)$ \\
\hline \multicolumn{2}{|l|}{ Type of comorbidity $(n=34)$} \\
\hline Hypertension & $16(47.0)$ \\
\hline Diabetes mellitus & $12(35.3)$ \\
\hline Respiratory problems & $4(I I .8)$ \\
\hline Migraine & $2(5.9)$ \\
\hline \multicolumn{2}{|l|}{ Difficulty in obtaining supplies $(n=130)$} \\
\hline Present & $72(55.4)$ \\
\hline
\end{tabular}

\begin{tabular}{ll}
\hline Characteristics & Frequency (\%) \\
\hline Reasons for difficulty in obtaining ostomy supplies $(\mathrm{n}=72)$ \\
Long distance to reach clinic & $42(58.33)$ \\
High price of the ostomy supplies & $15(20.83)$ \\
Long distance + high price & $12(16.67)$ \\
Inadequate number of supplies provided & $3(4.17)$ \\
Self-care efficacy ( $\mathrm{n}=130)$ & \\
Can care for oneself totally & $81(62.3)$ \\
Can care for oneself partially & $32(24.6)$ \\
Needs someone else completely & $17(13.1)$ \\
\hline
\end{tabular}

Abbreviations: max, maximum; min, minimum, SD, standard deviation.

psychosocial adjustment among ostomates, and the mean \pm SD score of acceptance, anxious preoccupation, social engagement, and anger were $22.01 \pm 6.99,8.75 \pm 3.89$, $5.38 \pm 3.41$, and $5.35 \pm 1.62$, respectively. Further analysis of the response to each subscale revealed various concerns.

\section{Acceptance subscale}

Approximately $38 \%$ of the ostomates strongly agreed that they felt recovered after the stoma operation. More than half (56.2\%) agreed that life was meaningful even with stoma, and $45.4 \%$ agreed that they accepted stoma as part of their body. However, only $23 \%$ strongly agreed that they enjoyed food and drink as much as before the surgery. Regarding sleeping difficulty, only one-quarter strongly agreed that they could sleep well without worrying about stoma. The majority of ostomates $(65.4 \%)$ agreed that they had accepted the changes in their appearance caused by stoma. Similarly, less than half $(41.5 \%$ and $49.2 \%)$ of them agreed that they were grateful that stoma had given them new life and that their life was worthwhile, respectively; yet, very few (3.1\%) agreed that they could participate in a variety of activities despite stoma.

\section{Anxious preoccupation subscale}

Approximately $37 \%$ of ostomates agreed that they will always be a patient due to stoma. Similarly, the majority of them (66.9\%) strongly agreed that they were always conscious that the stoma may leak, smell, or be noisy. Almost an equal number $(33.8 \%$ and $33.1 \%$ ) of ostomates agreed that they felt less sexually attractive and were always anxious about stoma, respectively.

\section{Social engagement subscale}

It was revealed that a similar number ( $45.4 \%$ and $46.9 \%)$ of ostomates strongly agreed that stoma made it difficult for them to bath, and it was not easy for them to mingle within society, respectively. Similarly, $33 \%$ agreed that they do not have control over their life. Likewise, less than half of the 
ostomates (46.9\%) strongly agreed that they had restricted activities due to stoma.

\section{Anger subscale}

Very few of the ostomates $(1.5 \%$ and $3.5 \%)$ strongly agreed that they did not like touching or seeing the stoma and they cannot get over the shock of having stoma, respectively.

\section{Research question 2: Does the psychosocial adjustment score differ by selected sociodemographic and clinical characteristics?}

To find out the difference in the psychosocial adjustment score in the subgroup of patients according to sociodemographic and clinical characteristics, independent sample $t$-test and one-way analysis of variance ( $F$-test) were employed. Moreover, the strength of the relationship between the psychosocial adjustment scores and continuous variable (time since surgery) was determined by using Pearson's correlation coefficients $(r)$.

Table 2 shows the association between selected sociodemographic and clinical variables with mean scores of psychosocial adjustment. Patients who were unemployed ( $t=2.042, P=0.04)$, perceived lack of family support $(t=4.093$, $P<0.01)$, had malignant disease as the reason for stoma ( $t=2.831, P=0.005)$, had ostomy for $<1$ year $(t=-3.806$, $P<0.001)$, and had difficulty in obtaining ostomy supplies $(t=-4.191, P<0.001)$ revealed significantly lower psychosocial adjustment score at $95 \%$ confidence intervals than their counterparts.

Interestingly, patients who were under treatment demonstrated lower psychosocial adjustment score than those who were not under treatment $(t=-3.888, P<0.001)$. Likewise, patients with lower self-efficacy had lower psychosocial adjustment scores than those having higher self-efficacy, and the differences were statistically significant $(F=17.965$, $P<0.001$ ) at $95 \%$ confidence intervals using one-way analysis of variance. Furthermore, the result of the correlation analysis showed that time since ostomy surgery was positively correlated $(r=0.422, P<0.001)$ with psychosocial adjustment.

\section{Research question 3: What are the predictors of psychosocial adjustment among patients with ostomy?}

Tables 3 and 4 show further analysis using multiple linear regression; it showed that only four variables contributed significantly to the final model explaining $46.8 \%$ of the variance in the psychosocial adjustment score, $\left(R^{2}=0.468, F\right.$ $[4,125]=27.53, P<0.001)$. It was found that perceived lack of family support $(\beta=-0.367, P<0.001)$, total dependence on others to care for ostomy $(\beta=-0.357, P<0.001)$, and unemployment ( $\beta=-0.144, P=0.032$ ) significantly predicted lower psychosocial adjustment score. However, increased time since ostomy surgery $(\beta=0.361, P<0.001)$ significantly predicted higher psychosocial adjustment scores.

\section{Discussion}

The present study examined the psychosocial adjustment in patients with ostomy visiting the selected stoma clinics of Nepal. The results showed that the mean $\pm \mathrm{SD}$ score in psychosocial adjustment scale was $41.49 \pm 13.57$, showing moderate impairment in the psychosocial adjustment among ostomates. A similar finding was noted in a previous study, ${ }^{4}$ wherein patients with ostomy had a mean \pm SD adjustment score of $49.84 \pm 12.48$, indicating a moderate level of psychosocial adjustment. By contrast, other studies ${ }^{5,6}$ reported good overall adjustment on social, occupational, and family concerns. The conflicting result should be interpreted by considering the differences in conceptualization of psychosocial adjustment, the use of different tools for measurement, and different timing during measurement in various studies.

Although overall psychosocial adjustment was moderately impaired, a detailed analysis of the subscales demonstrated multiple concerns in their life, where the majority of them had difficulties in sleeping, bathing, and enjoying foods and drinks as much as before the surgery. Most of them were conscious about stoma leakage, smell, or noise, which is consistent with previous studies. ${ }^{6,8}$ Restrictions in activities due to stoma, difficulty in mixing within society, and less sexual attraction were major concerns for them. They were particularly fearful about the reaction of others. This is a manifestation of phobic defense of restricting activities, unwillingness to leave home, and avoidance of others as suggested by Druss et al. ${ }^{16}$ Other studies also supported this finding. 6,34

Moreover, a few patients expressed that they were "Asuddha" [impure] because of the ostomy bag that they carried, and thus, they refrained themselves from performing religious activities. This is due to the effect of cultural value given to "Suddha" [pure] body for performing religious rituals in Nepal, where, to worship God, people often bath and even change their dress that had been worn during the elimination of body waste.

Nevertheless, the majority of the patients had accepted stoma as part of their body, including the changes associated 
Table 2 Difference on psychosocial adjustment scores according to patient characteristics $(n=130)$

\begin{tabular}{|c|c|c|c|c|}
\hline Patient characteristics & $\mathbf{N}$ & Mean score of psychosocial adjustment* & $T$ & $P$-value \\
\hline \multicolumn{5}{|l|}{ Age } \\
\hline$\leq 40$ years & 40 & 39.65 & -0.936 & 0.35 \\
\hline$>40$ years & 90 & 42.31 & & \\
\hline \multicolumn{5}{|l|}{ Sex } \\
\hline Male & 80 & 41.30 & -0.204 & 0.83 \\
\hline Female & 50 & 41.80 & & \\
\hline \multicolumn{5}{|l|}{ Employment status } \\
\hline Employed & 74 & 43.58 & 2.042 & 0.04 \\
\hline Unemployed & 56 & 38.73 & & \\
\hline \multicolumn{5}{|l|}{ Perceived family support } \\
\hline Present & 102 & 43.90 & 4.093 & $<0.001$ \\
\hline Absent & 28 & 32.71 & & \\
\hline \multicolumn{5}{|l|}{ Reason for formation of stoma } \\
\hline Benign disease & 16 & 50.25 & 2.831 & 0.005 \\
\hline Malignant disease & 114 & 40.26 & & \\
\hline \multicolumn{5}{|l|}{ Information about stoma before surgery } \\
\hline Received & 99 & 42.73 & $\mathrm{I} .872$ & 0.06 \\
\hline Not received & 31 & 37.55 & & \\
\hline \multicolumn{5}{|l|}{ Form of surgery } \\
\hline Planned & 83 & 41.14 & -0.387 & 0.68 \\
\hline Emergency & 47 & 42.11 & & \\
\hline \multicolumn{5}{|l|}{ Type of ostomy } \\
\hline Colostomy & 85 & 42.24 & $0.507^{\mathrm{a}}$ & $0.60^{\mathrm{a}}$ \\
\hline lleostomy & 15 & 38.60 & & \\
\hline Urostomy & 30 & 40.80 & & \\
\hline \multicolumn{5}{|l|}{ Time since ostomy surgery } \\
\hline $0.5-1$ years & 71 & 37.56 & -3.806 & $<0.001$ \\
\hline$>$ I year & 59 & 46.22 & & \\
\hline \multicolumn{5}{|l|}{ Treatment } \\
\hline Under treatment & 48 & 35.75 & -3.888 & $<0.001$ \\
\hline Not under treatment & 82 & 44.85 & & \\
\hline \multicolumn{5}{|l|}{ Complication related to ostomy } \\
\hline Present & 50 & 38.82 & -1.790 & 0.07 \\
\hline Absent & 80 & 43.16 & & \\
\hline \multicolumn{5}{|l|}{ Comorbidity } \\
\hline Present & 34 & 41.29 & -.099 & 0.92 \\
\hline Absent & 96 & 41.56 & & \\
\hline \multicolumn{5}{|l|}{ Difficulty in obtaining supplies } \\
\hline Yes & 72 & 37.28 & -4.191 & $<0.001$ \\
\hline No & 58 & 46.72 & & \\
\hline \multicolumn{5}{|l|}{ Self-care efficacy } \\
\hline Can care for oneself totally & 81 & 46.37 & $17.965^{\mathrm{a}}$ & $<0.00 I^{a}$ \\
\hline Can care for oneself partially & 32 & 34.59 & & \\
\hline Needs someone else completely & 17 & 31.24 & & \\
\hline
\end{tabular}

Notes: a Analysis of variance test, $P$-value significant at $<0.05$ level. *Higher scores indicated better adjustment. Bold values indicate a significant $P$-value $(<0.05)$.

with it and felt that it has given them a new life. Notably, acceptance is associated with better adjustment, since those who fail to accept, experience poor interpersonal relationships and are less likely to report improvements in adjustment to stoma surgery. ${ }^{7}$ Thus, this may explain why there was moderate impairment in overall score despite various problems reported.

It is obvious that ostomates have to face a double burden, disease as well as the challenging sequel of stoma. ${ }^{17-21}$ Thus, along with other factors, adjustment is most likely affected by the underlying disease as well as the treatment the patient is undergoing. The present study showed that those having malignant disease as a reason for stoma had a significantly lower psychosocial adjustment score than those having stoma due to other reasons. A possible explanation for this may be the stigma associated with cancer in the Asian context, where cancer is often described as an incurable disease and 
Table 3 Regression analysis for prediction of psychosocial adjustment from selected variables

\begin{tabular}{|c|c|c|c|c|}
\hline Predictor variables & $\begin{array}{l}\text { Unstandardized } \\
\beta \text { coefficient }\end{array}$ & $\begin{array}{l}\text { Standardized } \\
\beta \text { coefficients }\end{array}$ & $P$-value & $\begin{array}{l}95 \% \text { confidence } \\
\text { interval for } \beta\end{array}$ \\
\hline Constant & 48.691 & & $<0.001$ & 41.732 to 55.650 \\
\hline Employment status & -3.724 & -0.136 & 0.044 & -7.353 to -0.095 \\
\hline Perceived family support & -11 & -0.335 & $<0.001$ & $-|5.47|$ to -6.529 \\
\hline Reason for stoma & -0.891 & -0.022 & 0.768 & -6.869 to 5.087 \\
\hline Time since ostomy surgery & 1.041 & 0.326 & $<0.001$ & $0.54 I$ to $I .540$ \\
\hline Treatment & -1.060 & -0.038 & 0.614 & -5.205 to 3.085 \\
\hline Difficulty in obtaining supplies & -3.430 & -0.126 & 0.076 & -7.225 to 0.365 \\
\hline Self-care efficacy & -8.824 & -0.316 & $<0.001$ & -12.813 to -4.834 \\
\hline
\end{tabular}

Notes: $\mathrm{n}=$ I30; dependent variable: psychosocial adjustment. Bold values indicate a significant $P$-value $(<0.05)$.

Table 4 Final model resulting from regression analysis

\begin{tabular}{lllll}
\hline Predictor variables & $\begin{array}{l}\text { Unstandardized } \\
\boldsymbol{\beta} \text { coefficient }\end{array}$ & $\begin{array}{l}\text { Standardized } \\
\boldsymbol{\beta} \text { coefficients }\end{array}$ & P-value & $\begin{array}{l}\mathbf{9 5 \%} \text { confidence } \\
\text { interval for } \boldsymbol{\beta}\end{array}$ \\
\hline Constant & 46.023 & & $<0.001$ & 42.896 to 49.150 \\
Perceived family support & -12.083 & -0.367 & $<0.001$ & -16.340 to 7.827 \\
Time since ostomy surgery & 1.151 & 0.361 & $<0.001$ & 0.72 to 1.582 \\
Self-care efficacy & -9.951 & -0.357 & $<0.001$ & -13.73 to -6.171 \\
Employment status & -3.920 & -0.144 & 0.032 & -7.492 to -0.348
\end{tabular}

Notes: $\mathrm{n}=130 ; R^{2}=0.468$, adjusted $R^{2}=0.45 \mathrm{I}, \mathrm{F}$-value $(4,125)=27.536, P<0.00 \mathrm{I}$, Durbin-Watson $=1.767$; dependent variable: $p$ sychosocial adjustment.

considered synonymous with death. ${ }^{22}$ Even mentioning cancer is considered as a taboo. Thus, this can affect the psychological well-being and adjustment of patients who are dealing with cancer along with the other problems of stoma.

Interestingly, those who were under treatment reported a significantly lower psychosocial adjustment score than those who were not under treatment. This is attributable to the fact that the majority of those who were under treatment (95.8\%) had cancer, and $83.3 \%$ of them had ostomy for $<1$ year, where they have had to overcome the side effects of chemotherapy and radiation therapy. Considering the detrimental effects of cancer and its treatment, ${ }^{23,24}$ this is an expected finding. As anticipated, those having difficulty in obtaining supplies had significantly lower adjustment scores than those who had no difficulty. A major challenge for them was traveling long distance to reach a clinic $(58.33 \%)$ due to a lack of ostomy clinics and supplies for long-term use. Although these factors were associated with lower psychosocial adjustment in univariate analysis, they were not proved to be significant predictors in multivariate analysis. Subsequently, only four variables were proved to be significant predictors of psychosocial adjustment in the final model of regression analysis.

Perceived lack of family support was the major predictor of lower psychosocial adjustment score in this study. Those who perceived having no family support expressed that they were treated as a burden in the family, and they were deprived of financial and moral support. A few ostomates even expressed that they were considered dirty for having their bowel outside of their body and were forced to remain inside their own room. This can affect their psychological well-being, making it hard for them to accept their stoma and adjust, respectively. On the other hand, presence of family support can enhance one's acceptance, psychological well-being, and confidence to face society. The role of family support in adjustment is also supported by a study ${ }^{5}$ that examined the predictors influencing ostomy adjustment and found that adaptation was primarily affected by perceived support from family and significant others $(P=0.0002)$. Other studies also suggest that family support is essential for positive adjustment. ${ }^{2,11,12}$

Increased time since ostomy surgery significantly predicted a higher psychosocial adjustment score. In this study, the time since ostomy surgery ranged from 6 months to 25 years, mean time being 3.04 years. During the initial phase, they may have less information related to ostomy, underlying disease, available facilities, and prognosis than those having ostomy for a longer time. This could affect their anxiety level, social interactions, anger, acceptance, and how one adjusts to the changes brought by ostomy in their day-to-day life. A survey conducted in the $\mathrm{UK}^{15}$ also reported that time since surgery is a significant factor influencing adjustment 
$(P<0.001)$ among many other established factors. As the time since surgery increased, the level of psychosocial adjustment increased. Similar findings were reported in studies conducted in Chile and Taiwan. ${ }^{5,8}$

Likewise, the present study also identified total dependence on others to care for ostomy as a significant predictor of lower psychosocial adjustment score. This finding is in agreement with a study conducted in the People's Republic of China ${ }^{4}$ which reported a significant difference in psychosocial adjustment scores between the subjects who did and those who did not independently care for their own stoma $(P=0.005)$. Given the volume of evidence ${ }^{2,4,7,13}$ confirming the predictive effect of self-care ability on adjustment, it should be a major focus of the treatment in ostomates.

Finally, unemployment also significantly predicted a lower psychosocial adjustment score in the current study. Financial stability is essential in order to manage ostomy and its sequelae. Higher adjustment scores in those who were employed might be attributable to independence, affordability of ostomy supplies, and treatment services. One study ${ }^{2}$ supported this, where a higher income was associated with better adjustment $(r=0.26, P=0.02)$.

\section{Conclusion}

Ostomy often affects all aspects of a patient's life; however, emotional, sexual, and social lives are the most affected areas. Importantly, the focus of treatment of ostomates should expand beyond the physical boundaries and consider psychosocial concerns as well. The most important areas that need attention are the assessment of psychological and social concerns of ostomates on a regular basis, early identification of problems, and initiation of appropriate counseling programs as needed. Involvement of key family members and significant others in planning recovery programs for patients before discharge might be helpful to promote a successful adjustment. Provision of full information about the stoma and its self-care should be the prime focus of nursing intervention, and it should be promoted as early as possible. Affordability and accessibility of ostomy supplies demand attention from concerned authorities.

\section{Limitations}

Due to the design of this study, causality cannot be determined. The study may not reflect an overall picture of the many ostomates who have no access to stoma clinics. Power analysis was not carried out; thus, statistical power of the study may be open to question. The sample included in this study did not differentiate the first-time visitors or patients who had been to the clinic several times and had undertaken counseling services at the clinic. This could affect the degree of several problems that were examined in this study.

\section{Implication for practice}

This study might be helpful in preventing and reducing adjustment problems in ostomates by identifying the patients at risk, creating a supportive environment and using resources to help them effectively, or in making the necessary referrals. This paper can also help managers and policy-makers of hospitals to formulate strategies and programs to ensure a good adjustment of patients with ostomy.

\section{Acknowledgments}

The authors would like to thank Nursing Campus, Maharajgunj; Institutional Review Board of the Institute of Medicine, Tribhuvan University; BP Koirala Memorial Cancer Hospital; and Nepal Ostomy Association for providing an opportunity to conduct this study. Our sincere gratitude goes to Ms Kingsley L Simmons for granting permission to use the Ostomy Adjustment Inventory-23. We owe our thanks to all the ostomates who participated in this study.

\section{Disclosure}

The authors report no conflicts of interest in this work.

\section{References}

1. Brand M, Dujovny N. Preoperative considerations and creation of normal ostomies. Clin Colon Rectal Surg. 2008;21(1):5-16.

2. Bekkers MJTM, Van Knippenberg FCE, Van Dulmen AM, Van Den Borne HW, Van Berge Henegouwen GP. Survival and psychosocial adjustment to stoma surgery and nonstoma bowel resection: a four year follow-up. J Psychosom Res. 1997;42(3):235-244.

3. Pringle W, Swan E. Continuing care after discharge from hospital for stoma patients. Br J Nurs. 2001;10(19):1275-1288.

4. Cheng F, Meng AF, Yang LF, Zhang YN. The correlation between ostomy knowledge and self care ability with psychosocial adjustment in Chinese patients with a permanent colostomy. Ostomy Wound Manage. 2013;59(7):35-38.

5. Piwonka MA, Merino JM. A multidimensional modeling of predictors influencing the adjustment to a colostomy. JWound Ostomy Continence Nurs. 1999;26(6):298-305.

6. Haugen V, Bliss DZ, Savik K. Perioperative factors that affect long term adjustment to an incontinent ostomy. JWound Ostomy Continence Nurs. 2006;33(5):525-535.

7. Simmons KL, Smith JA, Bobb KA, Liles LL. Adjustment to colostomy: stoma acceptance, stoma care self-efficacy and interpersonal relationships. J Adv Nurs. 2007;60(6):627-635.

8. Li CC, Rew L, Hwang SL. The relationship between spiritual well being and psychosocial adjustment in Taiwanese patients with colorectal cancer and a colostomy. $J$ Wound Ostomy Continence Nurs. 2012;39(2):161-169.

9. Mahjoubi B, Moghimi A, Mirzaeli R, Bijari A. Evaluation of the end colostomy complications and the risk factors influencing them in Iranian patients. Colorectal Dis. 2005;7(6):582-587. 
10. Mahjoubi B, Mohammadsadeghi H, Mohammadipour M, Mirzaei R, Moini R. Evaluation of psychiatric illness in Iranian stoma patients. $J$ Psychosom Res. 2009;66:249-253.

11. Altschuler A, Ramirez M, Grant M, Wendel C, Hornbrook MC, Herrinton L, Krouse RS. The influence of husband's or male partner's support on women's psychosocial adjustment to having an ostomy resulting from colorectal cancer. JWound Ostomy Continence Nurs. 2009;36(3): 299-305.

12. Nichols TR. Social connectivity in those 24 months or less postsurgery. J Wound Ostomy Continence Nurs. 2011;38(1):63-68.

13. McVey J, Madill A, Fielding D. The relevance of lowered personal control for patients who have stoma surgery to treat cancer. Brit Psychol Soc. 2001;40(4):337-360.

14. Gautam HR, Bajracharya S. Psychosocial adjustment following ostomy in Nepal. J Soc Sur Nepal. 2003;6:26-29.

15. Simmons KL, Smith JA, Maewaka A. Development and psychometric evaluation of the Ostomy Adjustment Inventory-23. J Wound Ostomy Continence Nurs. 2009;36(1):69-76.

16. Druss RG, Conner JF, Stern LO. Psychologic response to colectomy. II. Adjustment to a permanent colostomy.. Arch Gen Psychiat. 1969; 20:419-427.
17. McMullen CK, Hornbook MC, Grant M, et al. The greatest challenges reported by long term colorectal cancer survivors with stomas. J Support Oncol. 2008;6(4):175-182.

18. Carlsson E, Berglund B, Nordgren S. Living with an ostomy and short bowel syndrome: practical aspects and impact on daily life. J Wound Ostomy Continence Nurs. 2001;28(2):96-105.

19. Popek S, Grant M, Gemmill R, et al. Overcoming challenges: life with an ostomy. Am J Surg. 2010;200(5):640-645.

20. Sinclair LG. Young adults with permanent ileostomies: experiences during the first four years after surgery. $J$ Wound Ostomy Continence Nurs. 2009;36(3):306-316.

21. Aronovitch SA, Sharp R, Morano LH. Quality of life for patients living with ostomies: influence of contact with an ostomy nurse. J Wound Ostomy Continence Nurs. 2010;37(6):649-653.

22. Randhwa G, Owens A. The meanings of cancer perceptions of cancer services among South Asians in Luton, UK. 2004;91(1):62-68.

23. Turns D. Psychosocial issues: pelvic exenterative surgery. J Surg Oncol. 2001;76(3):224-236.

24. Schneider EC, Malin JL, Kahn KL, Ko CY, Adams J, Epstein AM. Surviving colorectal cancer: patient-reported symptoms 4 years after diagnosis. Am Cancer Soc. 2007;110(9):2075-2082.
Nursing: Research and Reviews

\section{Publish your work in this journal}

Nursing: Research and Reviews is an international, peer-reviewed, open access journal publishing original research, reports, reviews and commentaries on all aspects of nursing and patient care. These include patient education and counseling, ethics, management and organizational issues, diagnostics and prescribing, health outcomes, economics and

\section{Dovepress}

resource management, improving patient safety in all settings. The manuscript management system is completely online and includes a very quick and fair peer-review system. Visit http://www.dovepress. $\mathrm{com} /$ testimonials.php to read real quotes from published authors. 